23. Steeper JR, Steuart CD 1981 A rapid assay for CDP reductase activity in mammalian cell extracts. Anal Biochem 34:123

24. Takeda E, Weber G 1981 Role of ribonucleotide reductase in expression of the neoplastic program. Life Sci 28:1007

25. Therander L, Reichard P 1979 Reduction of ribonucleotides. Annu Rev Biochem 48:133

26. Tice RR, Schneider EL, Kram D, Thorne P 1979 Cytokinetic analysis of the impaired proliferation responses of peripheral lymphocytes from aged humans to phytohemagglutinin. J Exp Med 149:1029

27. Tyrsted G, Gamulin V 1979 Cytidine 5'-diphosphate reductase activity in phytohemagglutinin stimulated human lymphocytes. Nucleic Acids Res $6: 305$
28. Weber G, Shiotani T, Kizaki H, Tzeng D, Williams JC, Gladstone N 1978 Biochemical strategy of the genome as expressed in regulation of pyrimidine metabolism. Adv Enzyme Regul 16:3

29. Weksler ME, Hutterroth TH 1974 Impaired lymphocyte function in aged humans. J Clin Invest 53:99

30. Informed consent was obtained for the families of all subjects in this study.

31. This work was supported by Grant 57770636 from the Ministry of Education, Science, and Culture of Japan.

32. Requests for reprints should be addressed to Dr. Eiji Takeda, Department of Pediatrics, Tokushima University, School of Medicine, Tokushima, Japan.

33. Received for publication February 1, 1984.

\title{
Bilirubin Photooxidation Products in the Urine of Jaundiced Neonates Receiving Phototherapy
}

\author{
DAVID A. LIGHTNER, ${ }^{(26)}$ WILLIAM P. LINNANE III, AND CHARLES E. AHLFORS \\ Department of Chemistry, University of Nevada, Reno, Nevada, USA and Section of Neonatology, Department of \\ Pediatrics, School of Medicine, University of California at Davis, Davis, California, USA
}

\section{Summary}

Bilirubin-IX $\alpha$ photooxidation products were detected by high performance liquid chromatography in the urine of neonates undergoing phototherapy for hyperbilirubinemia. The in vivo photoproducts were identified by chromatographic comparison with authentic synthetic standards using two complementary methods. Bilirubin photooxidation products were not detected in urine from jaundiced infants not receiving phototherapy. The specific photoproducts identified in the urine include propentdyopents, hematinic acid imide and its hydrolysis product (3-carboxy-2-methyl-2-hexenedioic acid), and the hydrolysis product (2-vinyl-3-methyl-maleic acid) of methylvinylmaleimide. Their total urinary concentrations were low $(0.2-0.9 \mathrm{mg} / \mathrm{dl})$ during phototherapy. These observations show that photooxidation of bilirubin clearly does occur during phototherapy. They are consistent with the view that, although photooxidation is not the major photochemical event associated with phototherapy, it can and clearly does occur concurrently with photoisomerization.

\section{Abbreviations}

UCB, unconjugated $(4 Z, 15 Z)$-bilirubin-IX $\alpha$

HPLC, high performance liquid chromatography

Phototherapy is used routinely in hospitals for treating neonatal jaundice (hyperbilirubinemia). Patients are irradiated with white or blue light to enhance elimination of the yellow cytotoxic metabolite $(4 Z, 15 Z)$-bilirubin-IX $\alpha$, which is produced in copious quantities in mammals by degradation of heme (2). Under normal metabolic conditions, UCB is detoxified by conjugation in the liver and excreted in bile. When conjugation is impaired, UCB accumulates in plasma and partitions into extravascular tissues, including the brain (23). About 150,000 infants per year in the United States develop plasma UCB levels of $15 \mathrm{mg} / \mathrm{dl}$ (3), and a large number of these receive some form of treatment (phototherapy) to remove or accelerate the excretion of UCB from the body, apparently reducing the risk of bilirubin encephalopathy (23).

The mechanism of UCB elimination in jaundice phototherapy has been investigated for many years. At first it was thought that the important photochemical event was accelerated catabolism of UCB to water-soluble derivatives that were excreted principally in bile and, to some extent, in urine (18). In this connection, a considerable effort was directed toward studies of bilirubin photooxidation $(7,21)$, wherein singlet oxygen, i.e. molecular oxygen in its first electronic excited state and known to be cytotoxic (25), was thought to be the oxidizing species (7). Recent data indicate that singlet oxygen may not be implicated and that bilirubin photooxidation may proceed via radical intermediates (6). Mechanistic questions aside, the products of in vitro photooxidation have been well characterized (7).

The widely held belief that bilirubin photodegradation is the responsible mechanism for lowering serum UCB in neonatal phototherapy (5) began to erode with the discovery of an apparent augmented excretion of UCB in the bile of Gunn rats (19) and jaundiced babies (10) undergoing light irradiation. This important finding was extremely intriguing because UCB normally cannot be excreted by the liver unless it is converted to polar conjugates, principally glucuronides (2). To accommodate the confirmed $(11,21)$ biliary excretion, $\boldsymbol{Z} \rightleftarrows \boldsymbol{E}$ photochemical configurational isomerization at the meso carbon-carbon double bonds of $(4 Z, 15 Z)$-bilirubin-IX $\alpha$ was proposed $(7,8)$ to give more polar $E$-isomers, isomers that could more easily cross the liver. The hypothesis was subsequently tested (15) and confirmed in Gunn rats $(12,24)$. More recently, the structures of the $\boldsymbol{E}$ isomers have been proved, and it has been shown that these isomers are formed in jaundiced rats exposed to blue light and in humans during phototherapy $(14,16)$. At present, current evidence favors the photochemical configurational isomerization of UCB (to $E$-isomers) as one of the most rapidly occurring photochemical events in phototherapy.

Of what importance is UCB photodegradation, however? In early studies with Gunn rats, Ostrow (20) suggested that UCB 
was photooxidized to smaller, more polar, water-soluble degradation products such as mono- and dipyrroles that were easily excreted. In support of that proposal, UCB photooxidation in vitro was examined, and many water-soluble photodegradation products were separated and characterized $(7,8)$. There is no conclusive evidence supporting the occurrence of UCB photooxidation in vivo during phototherapy, and no specific photooxidation products have been isolated and identified. Callahan $e t$ al. (3) reported the presence of polar, predominantly diazo- negative UCB photoproducts in bile and urine of congenitally jaundiced (Crigler-Najjar) infants undergoing phototherapy, but none of the products were identified. Ostrow (19) also reported finding UCB photoproducts in the bile and urine of (congenitally jaundiced) Gunn rats exposed to daylight fluorescent light. These, too, were not identified. Significantly, however, the Gunn rat urine gave a positive pentdyopent reaction following phototherapy, suggesting the presence of dipyrroles. Later, Onishi et al. (17) apparently found UCB photooxidation products in the

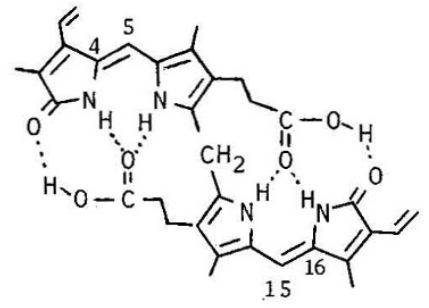

$(4 Z, 15 Z)-B I L I R U B I N-I X \alpha$<smiles>C=C/C(C(=O)O[Na])=C(\C)C(=O)O[Na]</smiles>

$\mathrm{R}=\mathrm{H}$ : $\mathrm{R}=\mathrm{CH}_{3}$ : (A) (a) ROOC<smiles>[R6]C1(/C=C2\[NH2+]C(=O)C(CCC)=C2C)NC(=O)C(C=C)=C1C</smiles><smiles>CC1=C(CCC(=O)O)C(=O)NC1=O</smiles>

(c)

(c)<smiles></smiles>

(D)

(d)<smiles>[R]OC(=O)OCCc1c[nH]c(CCCc2[nH]c(C=O)c(C)c2CCC(=O)O)c1C</smiles>

(E)

ROOC<smiles></smiles>

(G)

$(g)$<smiles>[R]OC(=O)CCC1=C(C)C(=CC2([R])NC(=O)C(C)=C2C=C)NC1=O</smiles>

$(\mathrm{H})$
(F)

(f) (g)

Fig. 1. Photodegradation products from photoxidation of bilirubin-IX $\alpha . A$, hydrolysis product of methylvinylmaleimide and its dimethyl ester (a). $B$, hydrolysis product of hematinic acid imide and its trimethyl ester $(b), C$, hematinic acid imide and its methyl ester $(c) . D=d$, methylvinylmaleimide. $E$, dipyrrole dialdehyde and its dimethyl ester $(e) . F$, exovinyl-B-water propentdyopent and its methanol propentdyopent methyl ester $(f) . G$, exovinyl-A-water propentdyopent and its methanol propentdyopent methyl ester $(g)$. $H$, endovinyl-B-water propentdyopent and its methanol propentdyopent methyl ester $(h)$. The methylated derivatives $a-h$ serve as standards for the HPLC detection of possible bilirubin photooxidation products $A-H$ in the urine of neonates.
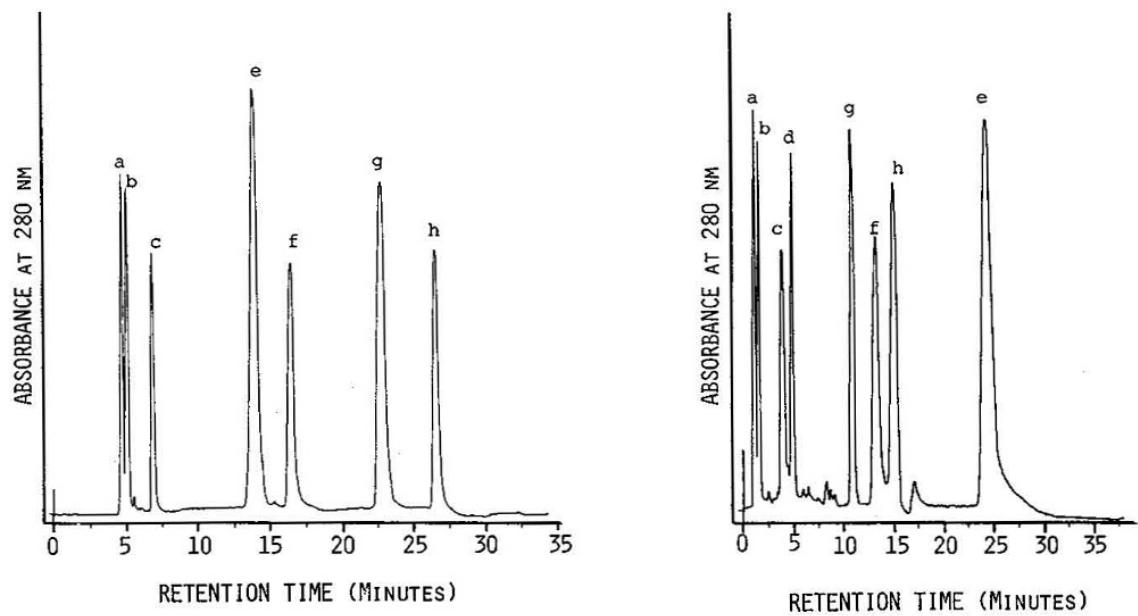

Fig. 2. HPLC scans of all reference standard bilirubin photooxygenation products using (left) a silica column, and (right) a reverse phase ODSC18 column. The letters on the scans refer to the standard reference compounds of Figure 1. The HPLC systems are described under "Materials and Methods." Methylvinylmaleimide is sensitive to and decomposes in the eluent solvent (chloroform-1\% acetic acid) used with the silica column, and thus peak $d$ does not appear in the chromatogram. 
blood, urine, and stools of "bronze" babies. Using HPLC, they found two prominent peaks in the urine, one corresponding to a tetrapyrrole, the other to a polymer. Apart from these early findings, no firm experimental evidence for UCB photooxidation during neonatal phototherapy has been published.

Although photoisomerization is held to be the major photochemical mechanism in vivo (5), continuous irradiation must unavoidably lead to some photooxidation (13). This being so, it seemed likely to us that such (polar, lower molecular weight) photoproducts would be excreted in urine. We have therefore analyzed urine samples from jaundiced infants undergoing phototherapy using newly developed, sensitive chromatographic techniques and well-characterized chemical standards that were not available to previous investigators. Our results show clearly that some photooxidation of UCB does occur during phototherapy.
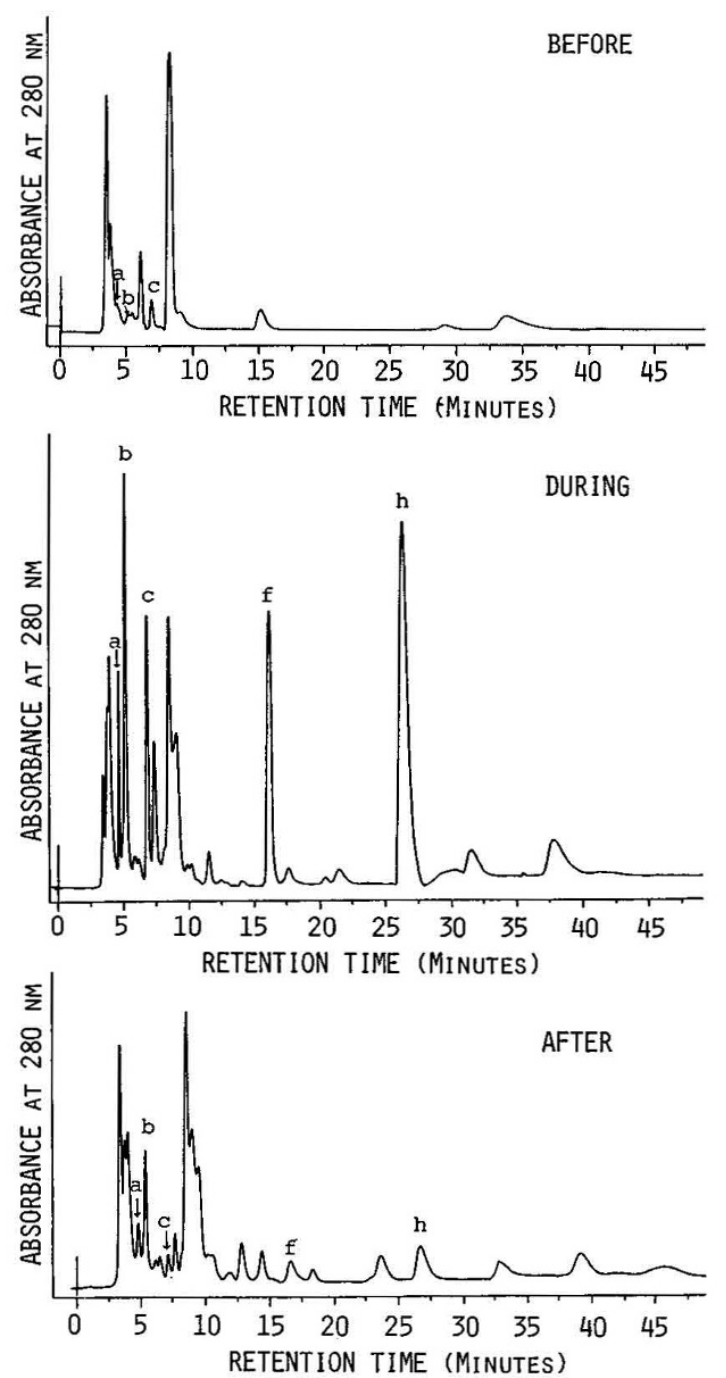

Fig. 3. HPLC (silica column) scans of urinary products. Top, sample taken $4 \mathrm{~h}$ after birth and before the onset of phototherapy. There are essentially no UCB photooxygenation products detected in this voiding. Middle, sample taken after $4 \mathrm{~h}$ into an 8-h phototherapy session. A dramatic growth of photoproducts is observed. Bottom, sample taken approximately $18 \mathrm{~h}$ after cessation of phototherapy. The infant is still voiding small amounts of UCB photooxygenation products. The intense unknown peak at 8.25 min serves as a convenient internal reference by which one can gauge the dramatic increase in UCB photoproducts during phototherapy. Arrows indicate the expected positions of the various standards, $a-h$ of Figure 1.

\section{MATERIALS AND METHODS}

Urine was collected (protected from light) from six jaundiced infants undergoing phototherapy and three jaundiced control infants not receiving phototherapy. The initial voiding was frozen as soon as possible and stored in the dark. Each additional voiding for that infant was added to the previously frozen voids until either phototherapy was discontinued or for about $12 \mathrm{~h}$ for the controls. The gestational ages of the infants undergoing phototherapy ranged from 27 to 39 weeks (with birth weights of $880-3180 \mathrm{~g}$ ), and those of the controls ranged from 26 weeks to term (with birth weights of $845-2860 \mathrm{~g}$ ). Eight were premature. Serum UCB levels of infants undergoing phototherapy ranged from 5.5 to $13.4 \mathrm{mg} / \mathrm{dl}$; those of the controls ranged from 3-8.6 $\mathrm{mg} / \mathrm{dl}$. One infant was studied before, during, and after phototherapy. One term infant with conjugated hyperbilirubinemia $(6.9 \mathrm{mg} / \mathrm{dl}$ direct reacting), who exhibited a positive urine diazo reaction and was not under phototherapy, was also studied.

The samples were lyophilized, and the residue was methylated in excess ethereal-methanolic diazomethane to form methyl esters of any existing carboxylic acid containing photoproducts and, at the same time, methanolyze any water-propentdyopents present (9). The solvent was rapidly evaporated and the residue was analyzed by a Perkin-Elmer Series 3 analytical HPLC equipped with: 1) a DuPont column $(25 \mathrm{~cm} \times 4.6 \mathrm{~mm}$ ID) packed with Zorbax-Sil 7- $\mu$ silica using an isocratic eluent of $1 \%$ acetic acid in Fisher HPLC grade chloroform (flow, $1.0 \mathrm{ml} / \mathrm{min}$; pressure 4-5.6 $\mathrm{mPa}$; detector, $280 \mathrm{~nm}$ ), and 2) a Knauer reverse phase column $(25 \mathrm{~cm} \times 4.6 \mathrm{~mm}$ ID) packed with $5-\mu$ ODS-C18 and an isocratic eluent of $26.9 \%$ Fisher HPLC grade acetonitrile inpurified water (flow, $1.0 \mathrm{ml} / \mathrm{min}$; pressure, $3.2 \mathrm{mPa}$; detector, $280 \mathrm{~nm}$ ). The HPLC analysis of a given sample involved dissolving one-half of the methylated urinary material in $2.0 \mathrm{ml}$ of chloroform (for the silica column) and the remaining half in acetonitrile (for the reverse phase column). The sample solutions $(25 \mu \mathrm{l})$ were injected on the appropriate column. For coinjection studies with UCB photooxidation standards (see below), the standards were dissolved in enough solvent to give $5 \mathrm{mg} / \mathrm{dl}$ concentrations. A sample $(25 \mu \mathrm{l})$ of standards solution was injected first and then followed with an injection of a mixture of $25 \mu \mathrm{l}$ of standards solution $+5 \mu \mathrm{l}$ of urinary sample. As many standard solutions $(5 \mu \mathrm{l}$ each) were coinjected as necessary for clarification and identification of the urinary sample components.

Reference standards were synthesized by photooxidation of bilirubin-IX $\alpha$ (Sigma) in methanolic ammonia (1\%) followed by rapid diazomethane methylation in the same manner as above (9). The standards were purified using preparative HPLC on a high flow DuPont column $(50 \mathrm{~cm} \times 25 \mathrm{~mm}$ ID) packed with 20 Lichrospheres coated with silica. The structures of the separated standard UCB photooxidation products were confirmed by comparison with previously reported reference standards $(7,8)$ and by their $100 \mathrm{MHz}{ }^{1} \mathrm{H}$ NMR spectra obtained from a JEOL FX100 instrument. A sample of the dipyrrole dialdehyde was provided by Dr. A. F. McDonagh, School of Medicine, University of California, San Francisco. The eight reference standards $(7,8)$ (shown in Fig. 1) include: the dimethyl ester of the hydrolysis product of methylvinylmaleimide (HPLC peak a), the trimethyl ester of the hydrolysis product of hematinic acid (HPLC peak b), hematinic acid methyl ester (HPLC peak c), methylvinylmaleimide (HPLC peak d), dipyrrole dialdehyde dimethyl ester (HPLC peak e), exovinyl-B-methanol propentdyopent methyl ester (HPLC peak f), exovinyl-A-methanol propentdyopent methyl ester (HPLC peak g), and endovinyl-B-methanol propentdyopent methyl ester (HPLC peak h).

Initially, a standard reference profile was obtained by injecting the reference standards into the HPLC in order to identify retention times (Fig. 2). Samples obtained from urine were then injected, and their components were matched with the reference standards by 1) comparison of retention times and 2) coinjection. The coinjection procedure served two useful purposes: 1) to 
Table 1. Methylated bilirubin photooxidation products ( $a, b, c, f$, and $h$; see Fig. 1) found in the urine of jaundiced neonates undergoing phototherapy and those found in jaundiced control neonates not undergoing phototherapy. All neonates had unconjugated hyperbilirubinemia. The products were identified and analyzed by HPLC on two different columns: silica and reverse phase ODS-C18 (see "Materials and Methods")

\begin{tabular}{|c|c|c|c|c|c|c|c|c|c|c|c|}
\hline \multirow[b]{2}{*}{ Infant } & \multicolumn{11}{|c|}{ Concentrations of products $(\mathrm{mg} / \mathrm{dl})$} \\
\hline & $\begin{array}{c}(a) \\
\text { Silica } \\
\text { ODS-C18 }\end{array}$ & Aver. & $\begin{array}{c}(b) \\
\text { Silica } \\
\text { ODS-C18 }\end{array}$ & Aver. & $\begin{array}{c}(c) \\
\text { Silica } \\
\text { ODS-C18 }\end{array}$ & Aver. & $\begin{array}{c}(f) \\
\text { Silica } \\
\text { ODS-C18 }\end{array}$ & Aver. & $\begin{array}{c}(h) \\
\text { Silica } \\
\text { ODS-C18 }\end{array}$ & Aver. & $\begin{array}{c}\text { Sum of } \\
\text { Average Conc. }\end{array}$ \\
\hline \multicolumn{12}{|c|}{ Phototherapy } \\
\hline 1 & $\begin{array}{l}0.095 \\
0.078\end{array}$ & 0.086 & $\begin{array}{l}0.483 \\
0.529\end{array}$ & 0.506 & $\begin{array}{l}0.311 \\
0.152\end{array}$ & 0.232 & $\begin{array}{l}0.086 \\
0.020\end{array}$ & 0.053 & $\begin{array}{l}0.084 \\
0.023\end{array}$ & 0.056 & 0.933 \\
\hline 2 & $\begin{array}{l}0.108 \\
0.097\end{array}$ & 0.102 & $\begin{array}{l}0.084 \\
0.073\end{array}$ & 0.078 & $\begin{array}{l}0.126 \\
0.074\end{array}$ & 0.100 & $\begin{array}{l}0.026 \\
0.038\end{array}$ & 0.032 & $\begin{array}{l}0.016 \\
0.001\end{array}$ & 0.009 & 0.321 \\
\hline 3 & $\begin{array}{l}0.038 \\
0.042\end{array}$ & 0.040 & $\begin{array}{l}0.022 \\
0.038\end{array}$ & 0.030 & $\begin{array}{l}0.164 \\
0.178\end{array}$ & 0.167 & $\begin{array}{l}0.064 \\
0.068\end{array}$ & 0.066 & $\begin{array}{l}0.006 \\
0.003\end{array}$ & 0.004 & 0.307 \\
\hline 4 & $\begin{array}{l}0.021 \\
0.022\end{array}$ & 0.022 & $\begin{array}{l}0.013 \\
0.148\end{array}$ & 0.082 & $\begin{array}{l}0.020 \\
0.214\end{array}$ & 0.117 & $\begin{array}{l}0.021 \\
0.056\end{array}$ & 0.039 & $\begin{array}{l}0.103 \\
0.040\end{array}$ & 0.072 & 0.332 \\
\hline 5 & $\begin{array}{l}0.031 \\
0.030\end{array}$ & 0.031 & $\begin{array}{l}0.050 \\
0.054\end{array}$ & 0.052 & $\begin{array}{l}0.065 \\
0.080\end{array}$ & 0.073 & $\begin{array}{l}0.078 \\
0.010\end{array}$ & 0.044 & $\begin{array}{l}0.001 \\
0.001\end{array}$ & 0.001 & 0.201 \\
\hline \multicolumn{12}{|c|}{ No phototherapy } \\
\hline 6 & $\begin{array}{l}0.045 \\
0.031\end{array}$ & 0.035 & $\begin{array}{l}0.032 \\
0.017\end{array}$ & 0.025 & $\begin{array}{l}0.011 \\
0.015\end{array}$ & 0.013 & & * & & $*$ & 0.073 \\
\hline 7 & $\begin{array}{l}0.014 \\
0.056\end{array}$ & 0.035 & $\begin{array}{l}0.056 \\
0.073\end{array}$ & 0.065 & $\begin{array}{l}0.041 \\
0.021\end{array}$ & 0.031 & & $*$ & & $*$ & 0.131 \\
\hline 8 & $\begin{array}{l}0.061 \\
0.060\end{array}$ & 0.061 & $\begin{array}{l}0.015 \\
0.054\end{array}$ & 0.035 & $\begin{array}{l}0.018 \\
0.025\end{array}$ & 0.022 & & * & & $*$ & 0.118 \\
\hline
\end{tabular}

* Not detected. Also not detected in any of the analyses above were $d, e$, and $g$.

establish a high degree of confidence that an "unknown" peak in the urine sample corresponds exactly with a reference standard by coinjection on both the silica column and the reverse phase column, and 2) to allow for direct calculations of the UCB photooxidation products in the urine samples by coinjection with reference standards of known concentration and volume.

\section{RESULTS}

Successful HPLC separation of all eight UCB photooxidation standards (Fig. 1, $a-h$ ) is shown in Figure 2. Only methylvinylmaleimide $(d)$ failed to appear on the silica column, because it decomposed in the solvent system used (chloroform-1\% acetic acid). Validity of analysis was checked using synthetic mixtures of $a-h)$. We could correctly detect and analyze for the components of the synthetic mixtures by coinjection of individual standards. Thus, it seemed likely that we could detect any of the known bilirubin photooxidation products $A-H$ ) should they appear in urine. The probability of correct matching and identification was increased by using two fundamentally different HPLC columns (with appropriate elution solvents): silica, for adsorption chromatography, and ODS-C18 for reverse phase or partition chromatography. Consequently, it is extremely unlikely that an unknown urinary component different from a given standard would show chromatographic behavior identical to the standard in both systems.

Typical HPLC scans to analyze for the presence of UCB photooxidation products in urine are presented in Figure 3. Analysis of methylated materials from urine taken from a neonate before, during, and after phototherapy is shown. The urine sample collected prior to phototherapy showed essentially none of the standards, either on a silica column (Fig. 3, top) or on a reverse phase column. Only trace amounts of the derivatized hydrolysis products of both methylvinylmaleimide and hematinic acid imide, $a$ and $b$, respectively, and hematinic acid imide (c) were found. On the other hand, a urine sample collected after $4 \mathrm{~h}$ of phototherapy, when the serum UCB was $10.3 \mathrm{mg} / \mathrm{dl}$, clearly shows the presence of UCB photooxidation products (Fig. 3 , middle). The peaks for $a, b$, and $c$ are markedly enhanced and new strong peaks appear for two propentdyopents, $f$ and $h$. (N.B.: the unknown intense peak at 8.25 min retention time may be used as an internal standard in all HPLC scans of Fig. 3.) The same photoproducts persisted to some extent (Fig. 3, bottom) up to $18 \mathrm{~h}$ after cessation of light therapy. Similar results for five other jaundiced infants with unconjugated hyperbilirubinemia and undergoing phototherapy are presented in Table 1 along with three control jaundiced patients with unconjugated hyperbilirubinemia and not undergoing phototherapy.

Urine samples from a neonate with conjugated hyperbilirubinemia $(6.9 \mathrm{mg} / \mathrm{dl})$ and not under lights showed (HPLC) no detectable amounts of any of the dipyrroles $(E-H)$ and only a trace of hematinic acid imide $(C)$, this with HPLC injection volumes three times greater than standard.

The concentrations of the various UCB photooxidation products (Fig. 1) found in urine and analyzed as their methylated derivatives are also given in Table 1 . The concentrations were determined by measuring HPLC peak areas and comparing them with the peak areas from sample + standard coinjections.

\section{DISCUSSION}

These studies provide the first clear, qualitative analytical proof that UCB photooxidation products (propentdyopents $F$ and $H$ ), hematinic acid imide $C$, its hydrolysis product $B$, and the hydrolysis product of methylvinylmaleimide $A$; Fig. 1) appear in the urine during phototherapy of human neonates with unconjugated hyperbilirubinemia (Table 1). The cited photooxidation products either do not arise or, as with the monopyrrole derivatives, occur to a lesser extent in jaundiced babies not undergoing phototherapy. And, except for a trace amount of hematinic acid imide $(C)$ detected as its methyl ester $(c)$, none of the UCB photodegradation products of Fig. 1 could be found in the urine of a full term baby with unconjugated hyperbilirubinemia not under phototherapy. We speculate that the origin of small quantities of hematinic acid imide $(C)$, its hydrolysis product $(B)$, and the hydrolysis product of methylvinylmaleimide $(A)$ may originate from UCB or its metabolic precursors via enzymatic oxidations $(22,23)$. Finding the hydrolysis product of methylvinylmaleimide $(A)$ in urine is probably evidence for formation of its precursor imide despite our failure to detect any $D$. However, methylvinylmaleimide $(D)$ is known to be unstable and may not survive long in vivo or during the experimental processing of the 
urine. The expected dipyrrole dialdehyde $(E)$ and propentdyopent $(G)$ were not found. The former may be formed in only extremely small amounts, much as it is apparently during in vitro bilirubin photooxidation (1), and below our threshold detection level. It is also unclear why the pentdyopent $G$ should not be found, especially when the isomeric propentdyopents $F$ and $H$ are. It may be that neither $E$ nor $G$ is formed at all.

The amounts (Table 1) of renally excreted UCB photooxidation products are small, in keeping with the distribution of excreted label following administration of $\left[{ }^{14} \mathrm{C}\right] U C B$ and light irradiation (19). If we assume also that only small amounts are formed in vivo, then our studies support the belief (5) that alternative photochemical pathways, e.g. configurational isomerization, are of greater importance in phototherapy. The studies demonstrate that UCB photooxidation occurs in vivo and is a component of phototherapy. And they identify for the first time known bilirubin photooxidation products in vivo.

\section{REFERENCES AND NOTES}

1. Bonnett R, Stewart JCM 1975 Photooxidation of bilirubin in hydroxylic solvents. J Chem Soc Perkin Trans I:224

2. Brown AK, McDonagh AF 1980 Phototherapy for neonatal hyperbilirubinemia: efficacy, mechanism and toxicity. Adv Pediatr 27:341

3. Callahan Jr EW, Thaler MM, Karon M, Bauer K, Schmid R 1970 Phototherapy of severe unconjugated hyperbilirubinemia: formation and removal of labeled bilirubin derivatives. Pediatrics $46: 841$

4. Chowdhury JR, Wolkoff AW, Arias IM $1982 \mathrm{Heme}$ and bile pigment metabolism. In: Arias IM, Popper H, Schachter D (eds) The Liver: Biology and Pathobiology. Raven Press, New York, pp 309-332

5. Cohen AN, Ostrow JD 1980 New concepts in phototherapy: photoisomerization of bilirubin IX $\alpha$ and potential toxic effects of light. Pediatrics 65:740

6. Landen GL, Park Y-T, Lightner DA 1983 On the role of singlet oxygen in the self sensitized photooxygenation of bilirubin and its pyrromethenone models. Tetrahedron 39:1893

7. Lightner DA 1982 Structure, photochemistry, and organic chemistry of bilirubin. In: Heirwegh KPM, Brown SB (eds) Bilirubin, vol I. CRC Press, Boca Raton, FL, pp 1-58

8. Lightner DA 1977 The photoreactivity of bilirubin and related pyrroles. Photochem Photobiol 26:427

9. Lightner DA, Quistad GB 1972 Hematinic acids and propentdyopents from bilirubin photooxidation in vitro. FEBS Lett 25:94

10. Lund HT, Jacobsen J 1974 Influence of phototherapy on the biliary bilirubin excretion pattern in newborn infants with hyperbilirubinemia. J Pediatr $85: 262$
11. McDonagh AF 1976 Photochemistry and photometabolism of bilirubin IX $\alpha$. In: Bergsma D, Blondheim SH (eds) Bilirubin Metabolism in the Newborn (II). Excerpta Medica, Amsterdam, pp 30-40

12. McDonagh AF, Palma LA 1980 Hepatic excretion of circulating bilirubin photoproducts in the Gunn rat. J Clin Invest 66:1181

13. McDonagh AF, Lightner DA, Wooldridge TA 1979 Geometric isomerization of bilirubin-IX $\alpha$ and its dimethyl ester. J Chem Soc Chem Commun 110

14. McDonagh Palma LA, Lightner DA 1982 Phototherapy for neonatal jaundice. Stereospecific and regioselective photoisomerization of bilirubin bound to human serum albumin and NMR characterization of intramolecularly cyclized photoproducts. J Am Chem Soc 104:6867

15. McDonagh AF, Palma LA, Lightner DA 1980 Blue light and bilirubin excretion. Science 208:145

16. McDonagh AF, Palma LA, Trull FR, Lightner DA 1982 Phototherapy for neonatal jaundice. Configurational isomers of bilirubin. J Am Chem Soc 104:6865

17. Onishi S, Fujikaka M, Ogawa Y, Ogawa J 1976 Photodegradation products of bilirubin studies by high pressure liquid chromatography, nuclear magnetic resonance and mass spectrometry. In: Bergsma D, Blondheim SH (eds) Bilirubin Metabolism in the Newborn (II). Excerpta Medica, Amsterdam, pp 41-52

18. Ostrow JD 1972 Photochemical and biochemical basis of the treatment of neonatal jaundice. In: Popper H, Schaffner D (eds) Progress in Liver Disease, vol IV. Grune and Stratton, New York, pp 447-462

19. Ostrow JD 1971 Photocatabolism of labelled bilirubin in the congenitally jaundiced (Gunn) rat. J Clin Invest 50:707

20. Ostrow JD 1967 Photo-oxidative derivatives of $\left[{ }^{14} \mathrm{C}\right]$ bilirubin and their excretion by the Gunn rat. In: Bouchier IAD, Billings B (eds) Bilirubin Metabolism. Blackwell Scientific, Oxford, pp 117-127

21. Ostrow JD, Berry CS, Knodell RG, Zarembo JE 1976 Effect of phototherapy on bilirubin excretion in man and in the rat. In: Bergsma D, Blondheim SH (eds) Bilirubin Metabolism in the Newborn (II). Excerpta Medica, Amsterdam, pp 81-92

22. Schmid R, Hammaker L 1963 Metabolism and disposition of $\mathrm{C}^{14}$-bilirubin in congenital nonhemolytic jaundice. J Clin Invest 42:2720

23. Schmid R, McDonagh AF 1978 Hyperbilirubinemia. In: Stanbury JB, Wyngaarden JB, Frederickson DS (eds) The Metabolic Basis of Inherited Diseases. McGraw-Hill, New York, pp 1221-1257

24. Stoll MS, Zenone EA, Ostrow JD 1981 Excretion of administered and endogenous photobilirubins in the bile of the jaundiced Gunn rat. J Clin Invest enous ph:134

25. Wasserman HH, Murray RW (eds) 1979 Singlet Oxygen. Academic Press, Inc., New York

26. Requests for reprints should be addressed to: Professor D. A. Lightner, Department of Chemistry, University of Nevada, Reno, Nevada 89557-0020.

27. This research was supported in part by National Institutes of Health Grants HD09026 and HD17779, and by National Science Foundation Grant CHE7910133.

28. Signed informed consent was obtained from parents of patients and controls. 29. Received for publication November 29, 1983. 